\title{
A Kalman filter approach to characterizing the Canadian term structure of interest rates
}

\author{
Toni Gravelle and James C. Morley ${ }^{\mathrm{b}, *}$ \\ anternational Monetary Fund \\ ${ }^{\mathrm{b}}$ Department of Economics, Box 1208, Washington University, \\ One Brookings Drive, St. Louis, MO 63130-4899, USA
}

This paper employs a Kalman filter approach to test the Expectations Hypothesis and characterize how term premia have changed over time for short-term Canadian interest rates. The Kalman filter approach is extended to account for changes in interest rate volatility, possible permanent changes in term premia, and overlapping forecast errors. The Expectations Hypothesis is strongly rejected with estimated term premia displaying significant time variation. There is some evidence of a positive relationship between term premia and interest rate volatility, although other macroeconomic and political factors are important, especially exchange rate volatility. Also, estimated term premia were actually negative during the late 1980 s.

\section{Introduction}

Broadly speaking, the Expectations Hypothesis is the idea that financial market expectations determine the shape of the term structure of interest rates. Modern studies of the hypothesis, beginning with Shiller (1979), have focused on a rational expectations formulation that allows for constant term premia. An implication of this formulation is that forward interest rates should be unbiased (up to constant term premia) predictors of future spot interest rates. Using standard linear regression tests, many empirical studies statistically reject forward rate unbiasedness for postwar US interest rates, although the evidence for other time periods and other countries, including for postwar Canadian interest rates, is more mixed. ${ }^{1}$ Cook and Hahn (1990) and Shiller (1990) provide excellent surveys of the literature.

This study pursues an alternative to the standard linear regression tests of forward rate unbiasedness in order to investigate the relevance of the Expectations Hypothesis to short-term Canadian interest rates. In particular, the Kalman filter is employed to extract unobserved term premia from excess forward returns (forward rates minus future realized spot rates) under an identifying assumption of rational expectations. Then, if the estimated term premia vary significantly over time, one can reject the Expectations Hypothesis. Iyer (1997) applies a similar approach to short-term US interest rates and rejects the Expectations Hypothesis. An earlier

\footnotetext{
*Corresponding author. E-mail: morley@wueconc.wustl.edu

${ }^{1}$ Notable studies that reject forward rate unbiasedness using postwar US data include Shiller et al. (1983), Fama (1984), Fama and Bliss (1987), Campbell and Shiller (1991), and Evans and Lewis (1994). Meanwhile, Mankiw and Miron (1986) do not reject using pre-First World War data and Mankiw (1986) and Hardouvelis (1994) generally do not reject using postwar data from other countries, including Canada, France, Germany, Italy, Japan and the UK.
} 
study by Wolff (1987) employs the same general approach to test for time-varying risk premia in forward exchange rates.

There are two reasons why the Kalman filter approach is considered. First, the few existing studies of short-term Canadian interest rates use traditional linear regression methods to test the Expectations Hypothesis and have produced strongly conflicting results. In particular, Paquette and Stréliski (1998) find supportive evidence for forward rate unbiasedness, while Gravelle et al. (1999) and Hejazi et al. (2000) reject it. The Kalman filter approach provides a new perspective on the issue. Second, given a failure of the Expectations Hypothesis, the Kalman filter approach allows us to estimate how term premia have evolved over time without prior specification of which factors cause term premia to change. This feature may be particularly useful for investigating short-term Canadian interest rates since they are likely affected by factors, such as political climate, that can be difficult to proxy with observables. ${ }^{2}$ This feature also helps us answer interesting questions about the relative importance of time-varying term premia in the determination of the shape of the term structure, the extent to which changes in term premia can be explained by changes in interest rate volatility and other economic and political factors, whether term premia were ever negative, and whether term premia behave similarly across the term structure. Ultimately, this characterization of term premia is every bit as important as simply determining whether the Expectations Hypothesis fails.

In order to address some specific issues that arise with the Canadian data, we extend the Kalman filter approach used in Wolff (1987) and Iyer (1997). First, we account for possible changes in interest rate volatility in the estimation of term premia. In particular, we assume a mixture of Normals distribution for market forecast errors. This specification appears to capture the behaviour of Canadian interest rates. It also allows one to test for interaction between term premia and interest rate volatility. Second, alternative time series specifications are considered for the unobserved term premia, including a random walk specification that accommodates the possibility of permanent changes in Canadian term premia. Allowing for permanent changes may be appropriate since Gravelle et al. (1999) find evidence of a unit root in Canadian term premia using the same data employed here. Third, overlapping market forecast errors are accommodated in the unobserved components models of excess forward returns used to estimate term premia. This last extension allows one examine the behaviour of term premia on actual observed forward contracts with settlement dates of more than one period in the future, rather than just the one-period-ahead case considered in previous Kalman filter studies. In this way, one is able to investigate a sizeable portion of the short end of the Canadian term structure.

The main findings can be summarized as follows. First, the Expectations Hypothesis is rejected for every forward horizon considered. The rejection is both statistically robust and economically relevant. Second, evidence is found that interest rate volatility has a positive effect on term premia, although it is clear that other macroeconomic and political factors are also important, especially exchange rate volatility. Third, the estimated term premia were actually negative during the late 1980s. This finding is notable because it potentially supports Modigliani and Sutch's (1966) 'preferred habitat' view of market preferences, although it could equally well reflect the presence of a 'peso problem' arising from a change in Canadian monetary policy regimes at that time. Either way, it should be noted that the rejection of the Expectations Hypothesis does not depend on the inclusion of data from the late 1980s in estimation.

The rest of the paper is organized as follows. Section II presents the model used to test the Expectations Hypothesis. Section III describes the data and presents the empirical results. Section IV concludes.

\section{Model}

\section{Background}

Let $f_{t, j}$ denote a forward interest rate set in period $t$ with cash settlement in period $t+j$. The lower case notation denotes a continuously compounded yield. Conceptually, a forward rate can always be decomposed as follows:

$$
f_{t, j}=E_{t}\left[r_{t+j}\right]+\tau_{t, j}
$$

where $E_{t}\left[r_{t+j}\right]$ is the conditional market expectation of the $j$-period-ahead spot rate given information available in period $t$ and $\tau_{t, j}$ is a residual premium on the forward contract, which is referred to as the 'term premium' because of its association with the term-to-settlement. ${ }^{3}$

\footnotetext{
${ }^{2}$ Interestingly, Shum (1995) finds a statistically significant relationship between poll information surrounding the 1992 constitutional referendum and Canadian interest rates.

${ }^{3}$ Since forward contracts are always considered on the same type of security (90-day Bankers' Acceptances), there is a strict link between term-to-settlement and the conventional notion of term-to-maturity.
} 
Subtracting the future realized spot rate from both sides of Equation 1 produces the following decomposition of a $j$-period excess forward return, denoted $x_{t+j, j} \equiv f_{t, j}-r_{t+j}$ :

$$
x_{t+j, j}=\tau_{t, j}+u_{t+j}
$$

where $u_{t+j} \equiv E_{t}\left[r_{t+j}\right]-r_{t+j}$ is a $j$-period market forecast error.

The Expectations Hypothesis can be thought of in terms of the restrictions it imposes on the two unobserved components of an excess forward return given in Equation 2. First, the term premium component is assumed to remain constant over time:

$$
\tau_{t, j}=\bar{\tau}_{j}
$$

This assumption corresponds to the idea that changes in market expectations are responsible for all changes in the shape of the term structure. Second, the market forecast errors are assumed to be uncorrelated with prior information:

$$
E_{t}\left[u_{t+j}\right]=0
$$

where the $E_{t}[$.$] operator refers to both the conditional$ market expectation and the mathematical expectation given a correctly specified conditional probability distribution. This assumption corresponds to the idea that financial market expectations are rational in the sense of Muth (1961).

One testable implication of the Expectations Hypothesis is forward rate unbiasedness. In particular, if forward rates are unbiased predictors of future spot rates, excess forward returns should not be predictable on the basis of predetermined information. Conversely, if term premia are time varying or market expectations are biased, excess forward returns should be predictable using forward rates or forward premia (forward rates minus current spot rates) since they embed both term premia and market expectations. Thus, a standard way to test the Expectations Hypothesis is to employ linear regression techniques to determine whether excess forward returns are predictable using forward rates or forward premia. In principle, any other predetermined variable can also be considered in analysis. However, data mining concerns and an axiomatic view of rational expectations tend to limit researchers to consider only factors that might plausibly affect term premia, such as conditional variances of financial and macroeconomic variables. In terms of the previous regression studies of shortterm Canadian term premia, Paquette and Stréliski (1998) use forward premia, Gravelle et al. (1999) use forward rates, ${ }^{4}$ and Hejazi et al. (2000) use forward premia and also consider ARCH measures of conditional variances of macroeconomic and financial variables. ${ }^{5}$

Another testable implication of the Expectations Hypothesis is that Kalman filter estimates of term premia from unobserved components models of excess forward returns based on Equation 2 and identified under the rational expectations assumption given in Equation 4 should not vary significantly over time. This alternative Kalman filter approach is considered instead of the standard regression approach for three reasons. First, regression based inferences about predictability are highly sensitive to the time series properties of regressors. For example, if forward rates or forward premia are integrated or 'nearly integrated' in the terminology of Cavanagh et al. (1995), standard $t$-tests and $F$-tests of predictability will suffer huge size biases, while accounting for such biases can eliminate any of their power. This issue appears to be less relevant for the Kalman filter approach since, as discussed below, it is found that the rejection of the Expectations Hypothesis is robust to different assumptions about the time series properties of the term premium component of forward rates and forward premia. Second, the standard regression approach requires identification of factors affecting term premia using observables. Meanwhile, it is highly plausible that term premia are affected by factors, such as political climate, that are difficult to proxy with observables. The Kalman filter approach allows us to estimate how term premia have evolved over time without any prior specification of such factors. In particular, we can fully characterize the behaviour of term premia, even if we do not directly identify the reasons for any changes. Third, under the rational expectations assumption, which implies predictable variation in excess forward returns reflects only changes in term premia, the standard regression approach does not account for the implied restrictions on the autocorrelation structure of excess forward returns. Meanwhile, the Kalman filter approach takes these implied restrictions into

\footnotetext{
${ }^{4}$ Technically, Gravelle et al. (1999) use a cointegration approach with a normalizing coefficient on the forward rate equal to one in the cointegrating vector for forward and spot rates. However, their approach is directly related to a regression of the spot rate on the forward rate.

${ }^{5}$ Lee (1995) takes a similar approach for the US data.
} 
account, leading to potentially more refined estimates of term premia. ${ }^{6}$

While the Kalman filter approach does not require prior specification of the factors that might cause term premia to change over time, it does require time series specifications for the unobserved components of excess forward returns. In particular, these specifications must satisfy the rational expectations assumption given in Equation 4 and they must nest the constant term premium assumption given in Equation 3. The various model specifications considered in this paper are presented next.

\section{Model specifications}

A total of four different specifications for the unobserved term premium are considered in Equation 2. These four specifications are labelled 'constant', 'nonstationary', 'stationary', and 'stationary/regimeswitching', respectively. The first three specifications are used to test the Expectations Hypothesis. The fourth specification is used to examine the interaction between term premia and changes in interest rate volatility. First, for the 'constant' specification, the term premium is assumed to be invariant over time, as in Equation 3. Second, for the 'nonstationary' specification, the term premium is assumed to follow a driftless random walk:

$$
\tau_{t, j}=\tau_{t-1, j}+v_{t}
$$

where $v_{t} \sim$ i.i.d. $N\left(0, \sigma_{v}^{2}\right)$ and the limiting case $\sigma_{v}^{2}=0$ corresponds to the 'constant' specification. Third, for the 'stationary' specification, the term premium is assumed to follow a stationary first-order autoregressive (AR) process:

$$
\tau_{t, j}=c+\phi \tau_{t-1, j}+v_{t}
$$

where $\phi$ is less than one in absolute value. Fourth, for the 'stationary/regime-switching' specification, the term premium is assumed to follow an AR(1) process with a regime switching intercept:

$$
\tau_{t, j}=c+\gamma S_{t+j}+\phi \tau_{t-1, j}+v_{t}
$$

where $S_{t+j}$ is a regime indicator variable that takes on values 0 or 1 depending on which interest rate volatility regime prevails in period $t+j$. The assumption that the current term premium depends on the future realized volatility regime, not its conditional expectation, should be seen as an approximation that is related to the finding in the next section of an independent switching specification for interest rate volatility. If volatility follows an independent switching process, conditional volatility will actually be constant and should not have a time-varying impact on the term premium. However, if $\gamma$ in Equation 7 is positive, it suggests that for agents the true conditional volatility is not constant, but at the same time it is not dependent on past volatility. That is, it implies that spikes in interest rate volatility are not persistent, but they can be (at least partially) predicted by economic agents. Given the finding in the next section that spikes in volatility often relate to fiscal concerns that build up over time and result in crises that cause interest rates to fluctuate wildly, it seems reasonable to assume that agents have some knowledge that crises will occur, if not literally the exact month in which they will occur, as is assumed in the specification in Equation 7. ${ }^{7}$ Empirically, the approximation in Equation 7 appears to work well as a way to capture what agents expect, while maintaining a specification that is consitent with the data in that it implies no persistence in interest rate volatility.

The decision to consider both stationary and nonstationary specifications warrants some further discussion. In terms of which specification is more appropriate, the relevant issue is not whether term premia are bounded and mean reverting. Instead, what is potentially relevant is the degree of mean reversion - i.e. the relative importance of permanent and transitory shocks to term premia. Given the short time span of the data set (1988-1998), the authors of the present study remain agnostic about this issue. On the one hand, they consider the nonstationary specification to accommodate the possibility that permanent shocks dominate. The findings in Evans and Lewis (1994) and Gravelle et al. (1999) on cointegration between spot and forward interest rates support this specification. Meanwhile, the random walk assumption represents a parsimonious way to allow for permanent shocks while being robust to misspecification as long as the true dynamics are persistent. ${ }^{8}$

\footnotetext{
${ }^{6}$ This point is motivated by the discussion in Nelson and Plosser (1982) of the implied restrictions on the autocorrelation function of the first differences of a random walk plus uncorrelated noise. In particular, the first differences should have an MA(1) structure, but the autocorrelation at lag one is bound between -0.5 and 0 . Maximum likelihood estimates for a univariate reduced-form MA(1) model of the first differences need not account for or even satisfy this restriction. By contrast, Kalman filter estimates for the random walk plus uncorrelated noise model will account for and satisfy this restriction.

${ }^{7}$ As an example, consider a political event like a constitutional referendum that has implications for future fiscal conditions. The timing of the referendum will be known in advance, although the outcome may not be known with certainty. Thus, agents can expect that when the outcome of the referendum is resolved, there will be a spike in interest rate volatility.

${ }^{8}$ See Garbade (1977) for an early Monte Carlo investigation of the consequences of misspecification.
} 
Also, the random walk assumption is more conservative than the stationary $\operatorname{AR}(1)$ assumption - or, for that matter, any other higher order $\operatorname{AR}(p)$ assumption, with or without a unit root - in attributing higher frequency movements in excess forward returns to term premia. Thus, it potentially provides the most convincing rejection of the Expectations Hypothesis. On the other hand, the stationary specification is considered to accommodate the possibility that term premia are strongly mean reverting. If this is the case, the estimates given an $\mathrm{AR}(1)$ assumption will more accurately reflect the true term premia. Also, the stationary specification allows one to directly examine the transitory effects of interest rate volatility on the levels of the term premia.

For the specification of the market forecast error term in Equation 2, a $(j-1)$ th-order moving average (MA) process with an independent switching variance is considered:

$$
u_{t+j}=\theta(L) e_{t+j}
$$

where

$$
\theta(L)=1+\theta_{1} L+\theta_{2} L^{2}+\cdots+\theta_{j-1} L^{j-1}
$$

and

$$
\begin{gathered}
e_{t+j} \mid S_{t+j} \sim N\left(0, \sigma_{t+j}^{2}\right) \\
\sigma_{t+j}^{2}=\sigma_{0}^{2}\left(1-S_{t+j}\right)+\sigma_{1}^{2} S_{t+j} \\
S_{t+j}=\{0,1\}, \operatorname{Pr}\left[S_{t+j}=0\right]=q
\end{gathered}
$$

Following convention, the MA coefficients are normalized to imply that $\theta(L)^{-1}$ exists. $S_{t+j}=0$ is also normalized to correspond to the low volatility regime (i.e. $\sigma_{0}^{2}<\sigma_{1}^{2}$ ). Thus, Equations $10-12$ imply that $e_{t+j}$ is drawn from a low variance distribution with probability $q$ and a high variance distribution with probability $1-q$, where $q$ is independent of past regimes or other prior information. As discussed in Morley (1999), the MA $(j-1)$ specification follows from the assumptions that all market forecast errors are serially uncorrelated with a mixture of Normals distribution and that forecast errors for the different future spot rates $r_{t+1}, r_{t+2}, \ldots, r_{t+j}$ are contemporaneously correlated.
For estimation, the study casts the various specifications of the model given by Equations 2, 9-12 and 3, 5-7, respectively, into state-space form and use a specialized version of Kim's (1994) filter and maximum likelihood methods. ${ }^{9}$ Kim's filter allows for regime switching in a state-space framework by combining the Kalman filter with Hamilton's (1989) filter for Markov-switching models. ${ }^{10}$ The study specializes the filter to the more restrictive case of independent switching. See the appendix for details.

\section{Empirical Results}

\section{Data}

The data used are end-of-the-month closing yields on Canadian 90-day Bankers' Acceptances and j-periodahead forward rate agreements $(j=1, \ldots, 9$ months $)$ on the Bankers' Acceptances from the Bank of Canada's data files. Paquette and Stréliski (1998) provide a thorough description of the data. The excess forward return series are constructed by taking the difference between the continuously compounded yield on a forward rate agreement and the subsequent realized continuously compounded yield on the underlying Bankers' Acceptance and multiplying by 100 to obtain percentages. The data set contains a total of 119 observations for each forward horizon, covering the period of August 1988 to June 1998.

There are four reasons why this data set is interesting. First, the existence of explicit forward contracts with settlement dates up to nine months in the future allows us to investigate a sizeable portion of the term structure. Second, the question of whether the Expectations Hypothesis holds for this data set is particularly relevant given the use of interest rates on three-month commercial paper in measuring the short-term orientation of Canadian monetary conditions. ${ }^{11}$ Third, the time period covered contains dramatic changes in factors, such as political climate, that are difficult to proxy with observables, but might affect term premia. Fourth, it is the same data set used in Paquette and Stréliski (1998) and Gravelle et al. (1999), allowing for direct comparison of the results.

\footnotetext{
${ }^{9}$ For all models in this paper, maximum likelihood estimation was conducted using the OPTMUM procedure for the GAUSS programming language. Numerical derivatives were used for the calculation of asymptotic standard errors. The variance and probability parameters were appropriately constrained. Inferences were robust to a variety of starting values.

${ }^{10}$ There are approximations involved in estimation via Kim's (1994) filter that arise from the switching variance of the MA errors. Similarly, if the MA errors had an ARCH distribution, estimation would involve the approximations discussed in Harvey et al. (1992). However, to the extent that accounting for a switching variance improves the efficiency of our estimates over assuming a constant variance, such approximations are justified.

${ }^{11}$ See Paquette and Stréliski (1998) and Gravelle et al. (1999) on this point.
} 

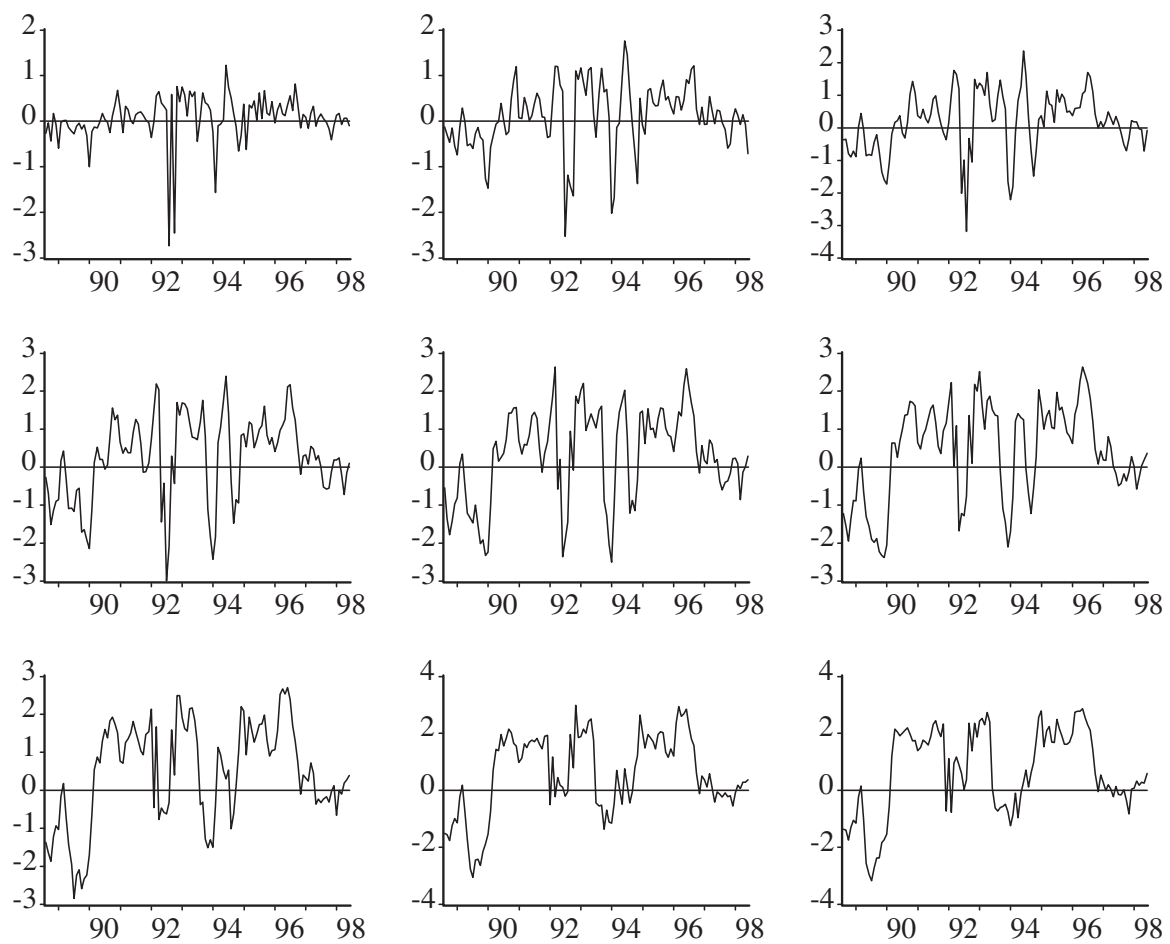

Fig. 1. Excess forward returns

Source: Spot and forward rates on Canadian 90-day Bankers' Acceptances are from the Bank of Canada data files. Data are expressed in percentage terms. Sample period is August 1988 to June 1998. Row 1 displays one-, two-, and three-month-ahead returns, respectively. Row 2 displays four-, five-, and six-month-ahead returns, respectively. Row 3 displays seven-, eight-, and nine-month-ahead returns, respectively.

Figure 1 displays the excess forward return series. Consistent with the MA $(j-1)$ implication discussed above, the series appear to become more persistent as the forward horizon increases. The series also appear to be subject to a few unusually large transitory shocks. Indeed, the Jarque and Bera (1980) test of Normality based on the third and fourth sample moments confirm this observation. The test statistic for the one-month-ahead returns is 739.80 , which given a $\chi^{2}(2)$ distribution under the null of Normality is quite significant. Table 1 presents estimates for three specifications of excess forward return volatility for one-month-ahead returns. ${ }^{12}$ Testing the null hypothesis of a constant variance against the alternative of independent switching produces a likelihood ratio statistic of 59.14. Even though the distribution is nonstandard since the probability $q$ is not identified under the null hypothesis
(Hansen, 1992; Garcia, 1998; Dufour and Luger, 1999), this test statistic far exceeds the asymptotic critical values reported in Garcia (1998) for more complicated alternative hypotheses. ${ }^{13}$ Importantly, the independent switching specification, which captures a very simple form of stochastic volatility, addresses the failure of Normality reported above. The Jarque and Bera (1980) statistic for the standardized returns in the presence of independent switching is only 3.36 , with a corresponding $p$-value of $0.19 .{ }^{14}$ At the same time, there are no lingering $\mathrm{ARCH}$ effects in the standardized returns. In particular, ARCH-LM statistics calculated as $T \cdot R^{2}$ for a regression of the standardized returns on $k$ lags of the standardized returns for $k=1,4$, and 12 are 1.21 , 7.19 , and 14.32, respectively. Given $\chi^{2}(k)$ distributions, the corresponding $p$-values are $0.27,0.13$, and 0.28 , respectively. Meanwhile, the likelihood ratio

\footnotetext{
${ }^{12}$ The implied MA structure of the multi-period returns makes it easiest to focus only on one-month-ahead returns when considering volatility specifications for the underlying forecast errors.

${ }^{13}$ For a Markov-switching mean and variance alternative, Garcia (1998) reports a 1\% asymptotic critical value of 17.52 .

${ }^{14}$ The standardized returns are not observed, but are estimated using maximum likelihood estimates and inferences about the probability of each regime.
} 
Table 1. Estimates for excess forward return volatility

\begin{tabular}{lccc}
\hline \multirow{4}{*}{ Parameters } & \multicolumn{2}{l}{ Volatility specifications } \\
\cline { 2 - 4 } & $\begin{array}{l}\text { Constant } \\
\text { variance }\end{array}$ & $\begin{array}{l}\text { Independent } \\
\text { switching }\end{array}$ & $\begin{array}{l}\text { Markov } \\
\text { switching }\end{array}$ \\
\hline$\sigma_{0}$ & 0.51 & 0.31 & 0.31 \\
& $(0.03)$ & $(0.03)$ & $(0.03)$ \\
$\sigma_{1}$ & - & 1.50 & 1.55 \\
& & $(0.43)$ & $(0.46)$ \\
$q$ & - & 0.92 & 0.92 \\
$p$ & - & $(0.04)$ & $(0.04)$ \\
& & & 0.00 \\
Log likelihood & -97.73 & -68.16 & -68.10 \\
\hline
\end{tabular}

Notes: The data are one-month-ahead excess forward returns from August 1988 to June 1998. Standard errors are reported in parentheses. For the Markov-switching specification, the parameter $q$ represents the probability of remaining in the low variance regime, while $p$ represents the probability of remaining in the high variance regime.

test for the null of independent switching against the alternative of Markov switching, which should have a standard distribution, is only 0.12 , with a corresponding $p$-value of 0.73 . Therefore, independent switching is used to capture changes in excess forward return volatility.

\section{Testing the expectations hypothesis}

Table 2 reports log-likelihood values for the four term premium specifications and the nine forward rate horizons. The results provide clear evidence against the Expectations Hypothesis. For instance, using the nonstationary specification as the alternative, the implied likelihood ratio statistics for the null hypothesis $H_{0}: \sigma_{v}^{2}=0$ range from 8.38 for the eightmonth-ahead case to as much as 24.08 for the one-month-ahead case. Given a $\chi^{2}(1)$ distribution, these statistics are all significant at better than a $1 \%$ level. Furthermore, it has long been argued (Kendell and Stuart, 1973) that using a $\chi^{2}(1)$ distribution for this particular test actually understates the true significance due to a bunching of the probability mass towards the origin under the null hypothesis. Therefore, the evidence against the Expectations Hypothesis is even stronger than standard $p$-values would suggest.
The failure of the Expectations Hypothesis is also evident from a graphical inspection of the estimated time-varying term premia. Figure 2 displays the smoothed inferences about the term premia for the nonstationary specification and the nine forward rate horizons. Figure 3 displays the smoothed inferences about the term premia for the stationary specification and the nine forward rate horizons. ${ }^{15}$ In both cases, there is significant variation in the term premia. Furthermore, the inferences are robust to the two specifications, implying that the main findings do not hinge upon a strong assumption about the degree of mean reversion. Meanwhile, the implied likelihood ratio statistics for the null of the random walk against the alternative of the AR(1) range from 4.50 for the four-month-ahead case to 7.25 for the eight-monthahead case. While these are significant by conventional standards, they are likely to be affected by the bias discussed in Dickey and Fuller (1981). Therefore, one avoids drawing any strong conclusions on whether or not term premia are stationary.

A statistical rejection always begs the question of whether the rejection is economically relevant. An attempt is made to answer this question for the Expectations Hypothesis by estimating the relative importance of time-varying term premia in the determination of the shape of the term structure. Consider the following decomposition of a forward premium, denoted $\varphi_{t, j} \equiv f_{t, j}-r_{t}$, which we obtain by subtracting the current spot rate from both sides of Equation 1:

$$
\varphi_{t, j}=E_{t}\left[r_{t+j}-r_{t}\right]+\tau_{t, j}
$$

Under the Expectations Hypothesis, the term premium is constant over time, implying that all variation in the forward premium is due to changes in market expectations. Conversely, the economic relevance of the failure of the Expectations Hypothesis can be gauged by comparing the estimated variation of forward premia to the estimated variation of term premia. Table 3 reports the results of such a comparison using the standard deviations of innovations to forward premia and nonstationary term premia. At all horizons, time-varying term premia explain a sizeable portion of the variation in forward premia, ranging from about $25 \%$ for the one-month-ahead case to over $80 \%$ for the five-month-ahead case. These results provide strong support for the idea that the failure of the Expectations Hypothesis is

\footnotetext{
${ }^{15}$ The smoothed (two-sided) inferences represent point estimates and $95 \%$ confidence bands conditional on all available sample information. In every case, the smoothed inferences were similar to the filtered (one-sided) inferences, which are conditional on information up to time $t$ only. The smoothed inferences are reported because they tend to better reflect the estimated degree of variability. For instance, they would remain constant if the estimated variance were zero.
} 
Table 2. Log-likelihood values

\begin{tabular}{lcccc}
\hline \multicolumn{5}{l}{ Term premia specifications } \\
\cline { 2 - 4 } Forward horizons & Constant & Nonstationary & Stationary & Stationary/regime-switching \\
\hline$j=1$ & -68.16 & -56.12 & -53.54 & -51.92 \\
$j=2$ & -97.55 & -89.09 & -86.43 & -84.55 \\
$j=3$ & -107.34 & -99.62 & -96.44 & -95.80 \\
$j=4$ & -107.87 & -101.33 & -99.08 & -97.64 \\
$j=5$ & -123.84 & -116.73 & -113.91 & -113.41 \\
$j=6$ & -11.47 & -105.71 & -102.98 & -102.75 \\
$j=7$ & -106.64 & -101.81 & -98.28 & -98.25 \\
$j=8$ & -108.90 & -104.71 & -101.08 & -101.06 \\
$j=9$ & -114.19 & -103.52 & -100.62 & -100.25 \\
\hline
\end{tabular}

Notes: Log-likelihood values are from filter output. For the nonstationary specification, term premia are assumed to follow a random walk. For the stationary specification, term premia are assumed to follow a stationary AR(1) process. For the stationary/regime-switching specification, term premia are assumed to follow a stationary AR(1) process with switching intercept.
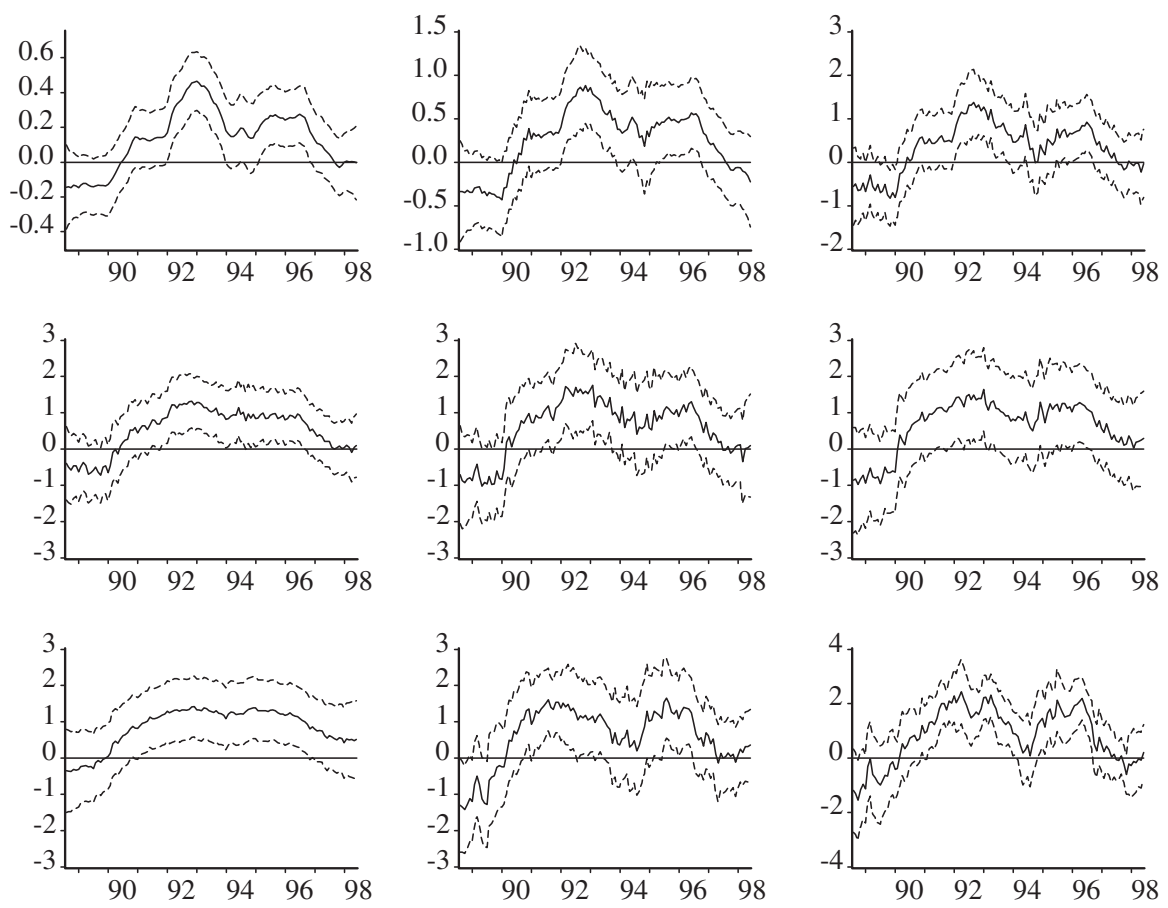

Fig. 2. Nonstationary term premia

Source: Smoothed inferences and 95\% confidence bands (dashed lines) are from filter output. Data are expressed in percentage terms. Sample period is August 1988 to June 1998. Row 1 displays term premia on one-, two-, and three-monthahead forward rate agreements, respectively. Row 2 displays term premia on four-, five-, and six-month-ahead forward rate agreements, respectively. Row 3 displays term premia on seven-, eight- and nine-month-ahead forward rate agreements, respectively. Term premia are assumed to follow a random walk.

economically relevant. They also motivate one to further investigate the behaviour of the estimated term premia.

\section{Term premia and interest rate volatility}

A particularly noticeable feature of Figs. 2 and 3 is that estimated term premia peak around the same time that excess forward returns appear most volatile in Fig. 1. Using the stationary/regime-switching specification for the term premium, the study formally investigates whether there is any interaction between term premia and interest rate volatility. The approach can be thought of as an alternative to Engle et al.'s (1987) ARCH-in-mean model that relates term premia to the conditional variance of 

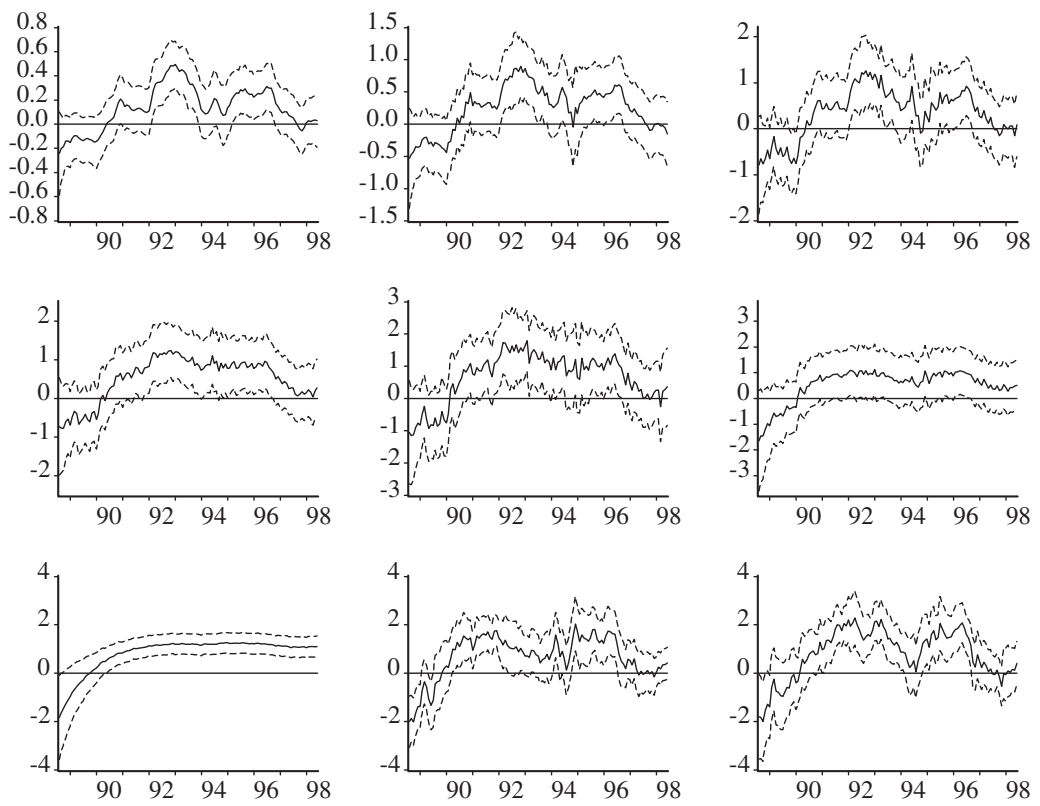

Fig. 3. Stationary term premia

Smoothed inferences and $95 \%$ confidence bands (dashed lines) are from filter output. Data are expressed in percentage terms. Sample period is from August 1988 to June 1998. Row 1 displays term premia on one-, two-, and three-month-ahead forward rate agreements, respectively. Row 2 displays term premia on four-, five-, and six-month-ahead forward rate agreements, respectively. Row 3 displays term premia on seven-, eight-, and nine-month-ahead forward rate agreements, respectively. Term premia are assumed to follow a stationary AR(1) process.

Table 3. Standard deviations of innovations to forward premia and nonstationary term premia

\begin{tabular}{lll}
\hline Forward horizons & $\sigma_{\Delta \varphi}$ & $\sigma_{v}$ \\
\hline$j=1$ & 0.20 & 0.06 \\
$j=2$ & 0.28 & 0.14 \\
$j=3$ & 0.32 & 0.25 \\
$j=4$ & 0.35 & 0.21 \\
$j=5$ & 0.38 & 0.32 \\
$j=6$ & 0.40 & 0.27 \\
$j=7$ & 0.42 & 0.15 \\
$j=8$ & 0.43 & 0.29 \\
$j=9$ & 0.44 & 0.33 \\
\hline
\end{tabular}

Notes: Standard deviations are expressed in percentage terms. Forward premia statistics are calculated using the first differences of the constructed series $\varphi_{t, j} \equiv f_{t, j}-r_{t}$. The term premia statistics are the maximum likelihood point estimates for the nonstationary specification.

excess holding returns. Hejazi et al. (2000) apply the ARCH-in-mean approach to Canadian data and find that conditional variances of Canadian macroeconomic and financial variables, including excess holding returns themselves, play little or no role in predicting term premia. ${ }^{16}$ One possible explanation for their result is that the ARCH specification does not capture the sudden changes in volatility that characterize the Canadian data. Of course, with less persistence comes less reason to expect any interaction between volatility and term premia.

Table 4 reports estimates for the stationary/ regime-switching specification for the one-month, two-month, and four-month forward horizons. The results in Table 2 suggest that the regime switching intercepts are only significant for these three horizons. In particular, the implied likelihood ratio statistics for the null hypothesis $H_{0}: \gamma=0$ are 3.25 for one-month-ahead case, with a $p$-value of 0.07 , 3.76 for the two-month-ahead case, with a $p$-value of 0.05 , and 2.88 for the four-month-ahead case, with a $p$-value of 0.09 . Note that these statistics should have a standard distribution since the MA errors are regime switching under both competing hypotheses. In each case, interest rate volatility has a large positive effect on the level of the term premium, as in Engle et al. (1987). Specifically, the estimates in Table 4 imply that a transition from a low volatility regime to a high volatility regime corresponds to an increase in the intercept for the three term premia by 25,55 , and 48 basis points, respectively.

\footnotetext{
${ }^{16}$ Interestingly, Hejazi et al. (2000) find that the conditional variances of US macroeconomic variables help predict Canadian term premia.
} 
Table 4. Estimates for stationary/regime switching specification

\begin{tabular}{llll}
\hline \multirow{4}{*}{ Parameters } & $j=1$ & $j=2$ & $j=4$ \\
\cline { 2 - 4 }$c$ & $0.01(0.02)$ & $0.01(0.02)$ & $0.01(0.04)$ \\
$\gamma$ & $0.25(0.25)$ & $0.55(0.29)$ & $0.48(0.21)$ \\
$\phi$ & $0.84(0.19)$ & $0.89(0.05)$ & $0.92(0.03)$ \\
$\sigma_{v}$ & $0.10(0.10)$ & $0.14(0.05)$ & $0.12(0.08)$ \\
$\theta_{1}$ & - & $0.82(0.05)$ & $1.07(0.05)$ \\
$\theta_{2}$ & - & - & $1.14(0.09)$ \\
$\theta_{3}$ & - & - & $0.92(0.08)$ \\
$\sigma_{0}$ & $0.22(0.04)$ & $0.32(0.04)$ & $0.31(0.04)$ \\
$\sigma_{1}$ & $1.67(0.56)$ & $2.25(0.55)$ & $1.67(0.92)$ \\
$q$ & $0.92(0.05)$ & $0.95(0.03)$ & $0.90(0.05)$ \\
Log likelihood & -51.92 & -84.55 & -97.64 \\
\hline
\end{tabular}

Notes: The data are one-, two-, and four-month-ahead excess forward returns from August 1988 to June 1998. Standard errors are reported in parentheses.

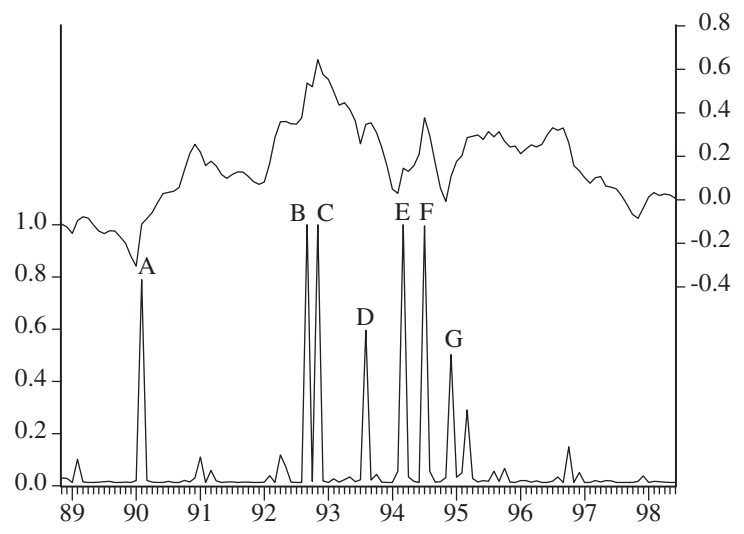

Fig. 4. A stationary/regime-switching term premium and the probability of a high volatility regime

Smoothed inferences are from filter output. Data are expressed in percentage terms. Sample period is from August 1988 to June 1998. The term premium is on a one-month-ahead forward rate agreement and is assumed to follow a stationary $\mathrm{AR}(1)$ process with switching intercept. The letters denote events listed in Table 5.

Figure 4 plots smoothed inferences about the term premium for the stationary/regime-switching specification and the one-month forward horizon against the probability of being in a high volatility regime. The purpose of this figure is to demonstrate the timing of the relationship between interest rate volatility and the term premium. For instance, there is a clustering of high volatility episodes in the middle of the sample coinciding with the period in which the estimated term premium was highest. Meanwhile, the absence of such volatile episodes at the end of the sample corresponds to a decline in the term premium. Very similar results are found for the two-monthahead and the four-month-ahead cases.

\section{Political and economic events and other} macroeconomic factors

An interesting question is whether the high volatility episodes in Fig. 4 have any correspondence to political and economic events that have impacted Canadian financial markets. Table 5 lists the events corresponding to the high volatility episodes displayed in Fig. 4. The table draws heavily from Clinton and Zelmer (1997) and Zelmer (1996), who provide a detailed list of political and economic events that have affected the Canadian/US exchange rate. The events range from market confusion over monetary policy signals, Standard and Poor' downgrading of Canadian sovereign debt, the failure of a national referendum on a constitutional amendment, market concerns over fiscal policy, and the December 1994 Mexican crisis that closely preceded international attention to Canada's fiscal situation when the Wall Street Journal ran the headline 'Bankrupt Canada?'

The nature of these events confirms our claim that many of the factors impacting term premia are difficult to proxy with observables. However, it is also clear from the estimates of $\sigma_{v}$ in Table 4 that most of the variation of term premia is due to factors other than the specific events listed in Table 5. While it is possible that these other factors are also difficult to proxy with observables, it is considered whether some of the macroeconomic fundamentals examined in Lee (1995) and Hejazi et al. (2000) have explanatory power for the behaviour of the estimated term premia. Lee (1995) considers a number of variables including the conditional volatilities of US industrial production and M1 as determinants of US term premia. Hejazi et al. (2000) examine Canadian term premia using variables including the conditional volatilities of both Canadian and US industrial production and M1 and the Canada/US exchange rate.

Table 6 reports estimates of $\operatorname{GARCH}(1,1)$ conditional volatility processes for the Canada/US exchange rate, Canadian (monthly) GDP, US M1, and US industrial production, where the GARCH model of conditional volatility $h$ has the form:

$$
h_{i, t}=\alpha_{0}+\alpha_{1} \varepsilon_{i, t-1}^{2}+\alpha_{2} h_{i, t-1},
$$

where $i=e x, y C A N, m U S, y U S$ for the four series, respectively, and $\varepsilon_{i, t}$ denotes the residual from the regression of the first differences of the logarithms of each series on a constant. The data are monthly and cover the sample period of August 1988 to June 1998. The exchange rate and Canadian GDP are from the Bank of Canada's data files and the US data are from the St. Louis Federal Reserve database. Canadian M1 is not included as preliminary analysis 
Table 5. Political and economic events

\begin{tabular}{|c|c|c|}
\hline Event & Date & Description \\
\hline A & February 1990 & Ease in monetary policy sparks inflation fears in market \\
\hline $\mathrm{B}$ & September 1992 & $\begin{array}{l}\text { Standard and Poor's downgrades Canada's foreign currency debt } \\
\text { from AAA to AA+ }\end{array}$ \\
\hline $\mathrm{C}$ & November 1992 & $\begin{array}{l}\text { Defeat of Charlottetown referendum on constitution and } \\
\text { ERM turbulence }\end{array}$ \\
\hline $\mathrm{D}$ & August 1993 & Political uncertainty ahead of federal election and ERM turbulence \\
\hline $\mathrm{E}$ & March 1994 & Market disappointment with federal budget \\
\hline $\mathrm{F}$ & July 1994 & Ongoing fiscal concerns \\
\hline G & December 1994 & Mexican crisis and 'Bankrupt Canada?' headline in Wall Street Journal \\
\hline
\end{tabular}

Note: The descriptions in this table are based on Clinton and Zelmer (1997).

Table 6. GARCH(1,1) estimates of macroeconomic fundamentals

GARCH $(1,1)$ model of conditional volatility:

$h_{i, t}=\alpha_{0}+\alpha_{1} \varepsilon_{i, t-1}^{2}+\alpha_{2} h_{i, t-1}$

\begin{tabular}{lccc}
\hline Variable $i$ & $\alpha_{0}$ & $\alpha_{1}$ & $\alpha_{2}$ \\
\hline Canada/US & 0.33 & 0.03 & 0.77 \\
Exchange rate $(e x)$ & $(0.39)$ & $(0.04)$ & $(0.25)$ \\
Canadian monthly & 0.08 & 0.10 & 0.80 \\
GDP $(y C A N)$ & $(0.10)$ & $(0.09)$ & $(0.16)$ \\
US M1 & 0.02 & 0.38 & 0.58 \\
$(m U S)$ & $(0.02)$ & $(0.21)$ & $(0.18)$ \\
US Industrial & 0.03 & 0.10 & 0.77 \\
Production $(y U S)$ & $(0.05)$ & $(0.09)$ & $(0.26)$ \\
\hline
\end{tabular}

Notes: The exchange rate and Canadian GDP series are from the Bank of Canada's data files and the US series are from the St. Louis Federal Reserve database. All data are converted to first differences of logarithms. The sample period is from August 1988 to June 1998. Standard errors are reported in parentheses.

revealed no evidence of heteroscedasticity over the sample period. The estimates in Table 6 are used to construct estimates of conditional volatilities.

To be consistent with the analysis in Lee (1995) and Hejazi et al. (2000), the time $t$ term premium on the time $t$ conditional expectation of volatility is regressed at time $t+1$. That is, the following model is considered:

$$
\begin{aligned}
\tau_{t, j}= & \beta_{0}+\beta_{e x} h_{e x, t+1}+\beta_{y C A N} h_{y C A N, t+1} \\
& +\beta_{m U S} h_{m U S, t+1}+\beta_{y U S} h_{y U S, t+1}+\varepsilon_{t}
\end{aligned}
$$

where, to be consistent (under the null that the $\beta_{i}$ are zero) with the stationary specification for the term premia, $\varepsilon_{t}$ is allowed to have first-order serial correlation:

$$
\varepsilon_{t}=\rho \varepsilon_{t-1}+\varepsilon_{t}^{*}
$$

where $\varepsilon_{t}^{*} \sim N\left(0, \sigma_{\varepsilon}^{2}\right)$.

Table 7 reports the results of OLS regression of (15) and (16) for the same three cases considered in
Table 4 (the stationary/regime-switching specification for the one-month, two-month, and four-month forward horizons). For each horizon, regressions with and without dummy variables are considered for events $A$ to $G$ that are listed in Table 5. Of the macroeconomic fundamentals, only exchange rate volatility is significant at the $5 \%$ level for the onemonth and two-month horizons. Furthermore, for the one-month horizon, it is only significant when the dummy variables for the events listed in Table 5 are excluded. That is, these events seem highly correlated with exchange rate volatility. The signs for the US fundamentals are generally, although not always, positive. Interestingly, the sign for the volatility of Canadian GDP is always negative, although the estimate is always highly insignificant, which is consistent with Hejazi et al.'s (2000) findings for Canadian Industrial Production.

Overall, the conclusion from these regression results is that political and economic events and macroeconomic fundamentals, especially exchange rate volatility, appear to play some role in determining term premia for short-term Canadian interest rates, but other factors that are difficult to proxy with observables are also important. The importance of unobservable factors justifies the Kalman filter approach as a way to characterize term premia when it is not possible to identify all of the specific factors driving them.

\section{Negative term premia}

Perhaps the most surprising feature of Figs. 2 and 3 is that the estimated term premia were negative in the early part of the sample. This finding, while clearly not statistically significant according to the $95 \%$ confidence bands, provides a serious challenge to the traditional view dating back to Lutz (1940) that term premia are always positive and increasing with maturity. Instead, it appears to support the 
Table 7. Term premia and macroeconomic fundamentals

\begin{tabular}{|c|c|c|c|c|c|c|}
\hline \multirow[b]{2}{*}{ Parameters } & \multicolumn{6}{|c|}{ Forward horizons } \\
\hline & $j=1$ & & $j=2$ & & $j=4$ & \\
\hline$\beta_{e x}$ & $0.16(0.06)$ & $0.06(0.08)$ & $0.29(0.13)$ & $0.34(0.19)$ & $0.02(0.12)$ & $0.02(0.17)$ \\
\hline$\beta_{y C A N}$ & $-0.07(0.04)$ & $-0.05(0.04)$ & $-0.10(0.10)$ & $-0.11(0.10)$ & $-0.07(0.09)$ & $-0.07(0.09)$ \\
\hline$\beta_{m U S}$ & $0.02(0.03)$ & $0.02(0.03)$ & $0.11(0.07)$ & $0.10(0.07)$ & $-0.04(0.07)$ & $-0.04(0.07)$ \\
\hline$\beta_{y U S}$ & $0.08(0.13)$ & $0.09(0.12)$ & $-0.14(0.28)$ & $-0.14(0.28)$ & $0.31(0.26)$ & $0.31(0.26)$ \\
\hline A & - & $0.09(0.04)$ & - & $0.07(0.09)$ & - & $-0.07(0.08)$ \\
\hline B & - & $0.06(0.05)$ & - & $-0.05(0.11)$ & - & $-0.04(0.11)$ \\
\hline $\mathrm{C}$ & - & $0.08(0.04)$ & - & $-0.04(0.09)$ & - & $0.03(0.09)$ \\
\hline $\mathrm{D}$ & - & $0.04(0.04)$ & - & $0.27(0.09)$ & - & $0.00(0.08)$ \\
\hline $\mathrm{E}$ & - & $0.06(0.04)$ & - & $0.11(0.09)$ & - & $-0.14(0.08)$ \\
\hline $\mathrm{F}$ & - & $0.12(0.04)$ & - & $0.16(0.09)$ & - & $-0.19(0.08)$ \\
\hline $\mathrm{G}$ & - & $0.02(0.04)$ & - & $-0.02(0.09)$ & - & $0.08(0.08)$ \\
\hline$\rho$ & $0.94(0.03)$ & $0.95(0.03)$ & $0.92(0.03)$ & $0.92(0.03)$ & $0.95(0.02)$ & $0.96(0.03)$ \\
\hline Adjusted $R^{2}$ & 0.92 & 0.93 & 0.90 & 0.90 & 0.97 & 0.97 \\
\hline
\end{tabular}

Notes: The data are (i) stationary with regime switching term premia for one-, two-, and four-month-ahead forward contracts, (ii) conditional volatilities based on Table 6, and (iii) dummy variables for events A through G listed in Table 5. The sample period is from August 1988 to June 1998. Standard errors are reported in parentheses. Bold denotes significance at the $5 \%$ level.

alternative view of Modigliani and Sutch (1966) that individuals can have different preferred investment horizons, or 'habitats', leading to the possibility of negative term premia in the event that market participants have a stronger preference for lending at longer horizons and borrowing at shorter horizons.

Of course, an alternative explanation for the findings is a possible small sample failure of the assumption underlying our identification of the term premia that market forecast errors are unbiased. ${ }^{17}$ This possibility is particularly relevant for Canadian interest rates given the circumstances surrounding the Bank of Canada's monetary policy in the late 1980s and early 1990s. Notably, in his 1988 Hanson Lecture, the then Governor of the Bank of Canada, John Crow, signaled a shift in policy emphasis toward price stability. This new stance culminated with the formal introduction of inflation reduction targets in February 1991. A plausible scenario, then, is that prior to the formal announcement of targets, financial markets were uncertain about the
Bank of Canada's commitment to its new stance. Thus, when the Bank of Canada initially raised interest rates before the targets were introduced, market participants may have anticipated a reversal of the Bank's position. The fact that the Bank did not reverse its position may have resulted in biased forecast errors as market participants repeatedly expected interest rates to fall when they subsequently did not.

This situation can be thought of as an example of the so-called 'peso problem' ${ }^{18}$ Specifically, suppose market participants believed that there was a significant probability of a future return to a more expansionary policy regime. Then, given that there was no return to this regime within the observed sample, expectations would appear irrational even though they were not. ${ }^{19}$ Meanwhile, our methodology would incorrectly attribute the small sample bias in the forecast errors to the term premia. Thus, the true term premia might have been positive during this early period even though our inferences suggest otherwise. It is only for the later period of our

\footnotetext{
${ }^{17}$ Another possible explanation is that, in the absence of strict Normality, the Kalman filter calculates a projection rather than a conditional expectation. Thus, the projection could be negative when the conditonal expectation is positive. However, two considerations argue against this explanation. First, unconditional Normality appears to hold reasonably well during the beginning of the sample when the estimated term premia are negative. Second, the filtered (one-sided) inferences also imply negative term premia during the beginning of the sample, which suggests that the negative estimates are not being unduly influenced by estimates from the periods in which unconditional Normality does fail due to independent switching.

${ }^{18}$ See Bekaert et al. (1997) for a discussion of the 'peso problem' and the Expectations Hypothesis.

${ }^{19}$ Of course, market expectations may have actually been irrational. Froot (1989) uses US survey data to show that market expectations as measured from the surveys are consistently biased, especially at short maturities. However, there are a number of problems with using survey data to measure 'the' market expectation.
} 
sample, when the Bank of Canada's inflation fighting credibility was fully established, that can be more confident in assuming that the inferences reflect the true term premia. However, it should be emphasized that, when the first two years are dropped from estimation, it is found that the likelihood ratio statistics were somewhat smaller, but still significant at conventional levels.

\section{Conclusions}

The results in this paper suggest that the Expectations Hypothesis can be rejected for short-term Canadian interest rates. The rejection is both statistically significant and economically relevant. Furthermore, the results shed new light on the extent to which changes in term premia can be explained by changes in political and economic factors and whether term premia were ever negative. On the first issue, we find that interest rate has some explanatory power and is related to other macroeconomic and political factors, but a large portion of the variation of term premia is due to other unobservable factors. On the second issue, we find that estimated term premia were actually negative during the late 1980s. However, the results and methodology leave open the question of whether the finding of negative term premia is a consequence of changes in 'preferred habitats' or the presence of a 'peso problem.'

Two other important issues that are not resolved in this paper are the extent to which term premia are mean reverting and the adequacy of the single factor representation of term premia at different maturities assumed in Tzavalis and Wickens (1997). On these issues, one only finds that the main results are robust to different assumptions about mean reversion and that the term premia in Figs. 2 and 3 behave similarly across the term structure. It is likely that estimation of term premia in a panel, rather than equation by equation, could shed additional light on these issues. However, this task is left for future research.

\section{Acknowledgements}

We would like to thank Richard Black, Charles Engel, Jean-François Fillion, Talan Iscan, Ming Chien Lo, Des Mc Manus, Charles Nelson, Dick Startz, David Watt, Mark Zelmer, Eric Zivot, and seminar participants at the Canadian Economics Association Meetings for helpful comments. Also, we would like to thank Paula Toovey for assistance with the Bank of Canada database. Responsibility for any errors is entirely our own. The views expressed in this paper are our own and should not be attributed to the IMF.

\section{References}

Bekaert, G., Hodrick, R. and Marshall, D. (1997) Peso problem explanations for term structure anomalies, Federal Reserve Bank of Chicago Working Paper 97-7.

Campbell, J. and Shiller, R. (1991) Yield spreads and interest rate movements: a birds eye view, Review of Economic Studies, 58, 495-514.

Cavanagh, C., Elliott, G. and Stock, J. (1995) Inference in models with nearly integrated regressors, Econometric Theory, 11, 1131-47.

Clinton, K. and Zelmer, M. (1997) Constraints on the conduct of Canadian monetary policy in the 1990s: dealing with uncertainty in financial markets, Bank of Canada Technical Report \#80.

Cook, T. and Hahn, T. (1990) Interest rate expectations and the slope of the money market yield curve, Federal Reserve Bank of Richmond Economic Review, 76, 3-26.

Dickey, D. and Fuller, W. (1981) Likelihood ratio statistics for autoregressive time series with a unit root, Econometrica, 49, 1057-72.

Dufour, J.-M. and Luger, R. (1999) Simulation-based finite and large sample tests for Markov switching autoregressive models, mimeo, University of Montreal.

Engle, R., Lilien, D. and Robins, R. (1987) Estimating time-varying premia in the term structure: the ARCH-M model, Econometrica, 55, 391-407.

Evans, M. and Lewis, K. (1994) Do stationary risk premia explain it all?, Journal of Monetary Economics, 33, 285-318.

Fama, E. (1984) The information in the term structure, Journal of Financial Economics, 13, 509-28.

Fama, E. and Bliss, R. (1987) The information in long maturity forward rates, American Economic Review, 77, 680-92.

Froot, K. (1989) New hope for the expectations hypothesis of the term structure of interest rates, Journal of Finance, 44, 283-305.

Garbade, K. (1977) Two methods for examining the stability of regression coefficients, Journal of the American Statistical Association, 72, 54-63.

Garcia, R. (1998) Asymptotic null distribution of the likelihood ratio test in Markov switching models, International Economic Review, 39, 763-88.

Gravelle, T., Muller, P. and Stréliski, D. (1999) Towards a new measure of interest rate expectations in Canada: estimating a time-varying term premium, in: Information in Financial Asset Prices, Proceedings of a Conference Held by the Bank of Canada, May 1998, 179-216.

Hamilton, J. (1989) A new approach to the economic analysis of nonstationary time series and the business cycle, Econometrica, 57, 357-84.

Hansen, B. (1992) The likelihood ratio test under nonstandard conditions: testing the Markov switching model of GNP, Journal of Applied Econometrics, 7, S61-82.

Hardouvelis, G. (1994) The term structure spread and future changes in long and short rates in the G7 countries, Journal of Monetary Economics, 33, 255-83. 
Harvey, A., Ruiz, E. and Sentana, E. (1992) Unobserved component time series models with ARCH disturbances, Journal of Econometrics, 52, 129-57.

Hejazi, W., Lai, H. and Yang, X. (2000) The Expectations Hypothesis, term premia, and the Canadian term structure of interest rates, Canadian Journal of Economics, 33, 133-48.

Iyer, S. (1997) Time-varying term premia and the behaviour of forward interest rate prediction errors, Journal of Financial Research, 20, 503-7.

Jarque, C. and Bera, A. (1980) Efficient tests for normality, heteroskedasticity, and serial independence of regression residuals, Economics Letters, 6, 255-59.

Kendall, M. and Stuart, A. (1973) The Advanced Theory of Statistics, Vol. 2, 3rd edn, Hafner Publishing Co., New York.

Kim, C.-J. (1994) Dynamic linear models with Markovswitching, Journal of Econometrics, 60, 1-22.

Kim, C.-J. and Nelson, C. (1999) State-Space Models with Regime Switching: Classical and GibbsSampling Approaches with Applications, MIT Press, Cambridge, MA.

Lee, S.-S. (1995) Macroeconomic sources of time-varying risk premia in the term structure of interest rates, Journal of Money, Credit, and Banking, 27, 549-69.

Lutz, F. (1940) The structure of interest rates, Quarterly Journal of Economics, 55, 36-63.

Mankiw, G. (1986) The term structure of interest rates revisited, Brookings Papers on Economic Activity, 1, 61-91.

Mankiw, G. and Miron, J. (1986) The changing behaviour of the term structure of interest rates, Quarterly Journal of Economics, 101, 211-42.

Modigliani, F. and Sutch, R. (1966) Innovations in interest rate policy, American Economic Review, 56, 178-97.

Morley, J. (1999) Essays in Empirical Finance, PhD dissertation, University of Washington.

\section{Appendix}

For illustration, the state-space form and estimation details are presented for the most general case of the model. In particular, the stationary/regime switching specification is considered. The other specifications simply represent restricted versions of this case. A given $j$-period-ahead forward horizon is assumed.

Equations 2 and 8 imply the following observation equation:

$$
x_{t+j, j}=\left[\begin{array}{lllll}
1 & 1 & \theta_{1} & \cdots & \theta_{j-1}
\end{array}\right]\left[\begin{array}{c}
\tau_{t, j} \\
e_{t+j} \\
e_{t+j-1} \\
\vdots \\
e_{t+1}
\end{array}\right],
$$

or, more compactly,

$$
y_{t}=H \beta_{t} .
$$

Muth, J. (1961) Rational expectations and the theory of price movements, Econometrica, 29, 315-35.

Nelson, C. and Plosser, C. (1982) Trends and random walks in macroeconomic time series, Journal of Monetary Economics, 10, 139-62.

Paquette, J.-Y. and Stréliski, D. (1998) The use of forward rate agreements in Canada, Bank of Canada Review, Spring, 57-71.

Shiller, R. (1979) The volatility of long-term interest rates and expectations models of the term structure, Journal of Political Economy, 87, 1190-219.

Shiller, R. (1990) The term structure of interest rates, in Handbook of Monetary Economics, Vol. 1 (Eds) B. Friedman and F. Hahn, North-Holland, Amsterdam, pp. 627-723.

Shiller, R., Campbell, J. and Schoenholtz, K. (1983) Forward rates and future policy: interpreting the term structure of interest rates, Brookings Papers on Economic Activity, 1, 173-217.

Shum, P. (1995) The 1992 Canadian Constitutional Referendum: using financial data to assess economic consequences, Canadian Journal of Economics, 28, 794-807.

Tzavalis, E. and Wickens, M. (1997) Explaining the failures of the term spread models of the rational expectations hypothesis of the term structure, Journal of Money, Credit, and Banking, 29, 364-80.

Wolff, C. (1987) Forward foreign exchange rates, expected spot rates, and premia: a signal-extraction approach, Journal of Finance, 42, 395-406.

Zelmer, M. (1996) Strategies versus tactics for monetary policy operations, in Money Markets and Central Bank Operations, Proceedings of a Conference Held by the Bank of Canada, November 1995, pp. 211-60.

Equations (7), and (10) imply the following state equation:

$$
\begin{aligned}
{\left[\begin{array}{c}
\tau_{t, j} \\
e_{t+j} \\
e_{t+j-1} \\
\vdots \\
e_{t+1}
\end{array}\right]=} & {\left[\begin{array}{c}
c+\gamma S_{t+j} \\
0 \\
0 \\
\vdots \\
0
\end{array}\right]+\left[\begin{array}{ccccc}
\phi & 0 & 0 & \cdots & 0 \\
0 & 0 & 0 & \cdots & 0 \\
0 & 1 & 0 & \cdots & 0 \\
\vdots & \ddots & \ddots & \ddots & \vdots \\
0 & 0 & 0 & \cdots & 0
\end{array}\right] } \\
& \times\left[\begin{array}{c}
\tau_{t-1, j} \\
e_{t+j-1} \\
e_{t+j-2} \\
\vdots \\
e_{t}
\end{array}\right]+\left[\begin{array}{c}
v_{t} \\
e_{t+j} \\
0 \\
0 \\
0
\end{array}\right],
\end{aligned}
$$

or, more compactly,

$$
\beta_{t}=\tilde{\mu}\left(S_{t+j}\right)+F \beta_{t-1}+\tilde{v}_{t},
$$


and the following variance-covariance matrix for the state equation:

$$
Q\left(S_{t+j}\right)=E\left[\tilde{v}_{t} \tilde{v}_{t}^{\prime}\right]=\left[\begin{array}{ccccc}
\sigma_{v}^{2} & 0 & 0 & \cdots & 0 \\
0 & \sigma_{t+j}^{2} & 0 & \cdots & 0 \\
0 & 0 & 0 & \cdots & 0 \\
\vdots & \vdots & \vdots & \ddots & 0 \\
0 & 0 & 0 & \cdots & 0
\end{array}\right]
$$

In terms of the compact notation, the Kalman filter portion of Kim's (1994) filter is given as follows:

$$
\begin{gathered}
\beta_{t \mid t-1}\left(S_{t+j}\right)=\tilde{\mu}\left(S_{t+j}\right)+F \beta_{t-1 \mid t-1} \\
P_{t \mid t-1}\left(S_{t+j}\right)=F P_{t-1 \mid t-1} F^{\prime}+Q\left(S_{t+j}\right) \\
\eta_{t \mid t-1}\left(S_{t+j}\right) \equiv y_{t}-H \beta_{t \mid t-1}\left(S_{t+j}\right) \\
f_{t \mid t-1}\left(S_{t+j}\right)=H P_{t \mid t-1}\left(S_{t+j}\right) H^{\prime} \\
\beta_{t \mid t}\left(S_{t+j}\right)=\beta_{t \mid t-1}\left(S_{t+j}\right)+K_{t}\left(S_{t+j}\right) \eta_{t \mid t-1}\left(S_{t+j}\right) \\
P_{t \mid t}\left(S_{t+j}\right)=P_{t \mid t-1}\left(S_{t+j}\right)-K_{t}\left(S_{t+j}\right) H P_{t \mid t-1}\left(S_{t+j}\right),
\end{gathered}
$$

where $\beta_{t \mid t-1}\left(S_{t+j}\right)$ is the expectation of $\beta_{t}$ conditional on information up to time $t-1$ and $S_{t+j} ; P_{t \mid t-1}\left(S_{t+j}\right)$ is the variance-covariance matrix of $\beta_{t \mid t-1}\left(S_{t+j}\right)$; $\eta_{t \mid t-1}\left(S_{t+j}\right)$ is the conditional forecast error; $f_{t \mid t-1}\left(S_{t+j}\right)$ is the variance-covariance matrix of $\eta_{t \mid t-1}\left(S_{t+j}\right)$; and $K_{t}\left(S_{t+j}\right) \equiv P_{t \mid t-1}\left(S_{t+j}\right) H^{\prime} f_{t \mid t-1}\left(S_{t+j}\right)^{-1}$ is the Kalman gain.

The Hamilton (1989) filter portion of Kims (1994) filter is given as follows:

$$
\begin{aligned}
& f\left(y_{t} \mid S_{t+j}\right)=\frac{1}{\sqrt{2 \pi f_{t \mid t-1}\left(S_{t+j}\right)}} \exp \left(-\frac{1}{2} \cdot \frac{\eta_{t \mid t-1}\left(S_{t+j}\right)^{2}}{f_{t \mid t-1}\left(S_{t+j}\right)}\right), \\
& (\mathrm{A} 10) \\
& f\left(y_{t}\right)=(1-p) \cdot f\left(y_{t} \mid S_{t+j}=0\right)+p \cdot f\left(y_{t} \mid S_{t+j}=1\right),
\end{aligned}
$$

with the updated probability that $S_{t+j}=i, i=\{0,1\}$ given by

$$
\operatorname{Pr}\left[S_{t+j}=i \mid y_{t}\right]=\frac{f\left(y_{t} \mid S_{t+j}=i\right)}{f\left(y_{t}\right)} .
$$

To complete the modified version of Kim's (1994) filter, one needs to collapse $\beta_{t \mid t}\left(S_{t+j}\right)$ and $P_{t \mid t}\left(S_{t+j}\right)$ across both states of the world. That is,

$$
\begin{gathered}
\beta_{t \mid t}=\sum_{i=0}^{1} \operatorname{Pr}\left[S_{t+j}=i \mid y_{t}\right] \cdot \beta_{t \mid t}(i), \\
P_{t \mid t}=\sum_{i=0}^{1} \operatorname{Pr}\left[S_{t+j}=i \mid y_{t}\right] \cdot\left\{P_{t \mid t}(i)+\left(\beta_{t \mid t}-\beta_{t \mid t}(i)\right)^{2}\right\} .
\end{gathered}
$$

The approach to estimation of this model is to iterate through equations (A.4)-(A.14) for $t=1,2, \ldots T$. Note that for starting up the filter, unconditional expectations of variables is used. ${ }^{20}$ Then, the marginal density function of $y_{t}$ given in Equation A.11 is used to find maximum likelihood estimates of the parameters. That is,

$$
\max _{\Pi} l(\Pi)=\sum_{t=1}^{T} \ln \left(f\left(y_{t}\right)\right)
$$

where $\Pi$ represents a vector of the parameters.

Finally, smoothed inferences are obtained by iterating the following two equations backwards from $T$ to 1 :

$$
\begin{aligned}
\beta_{t \mid T}\left(S_{t+j}\right) & =\beta_{t \mid t}+\tilde{P}_{t}\left(S_{t+j}\right)\left(\beta_{t+1 \mid T}-\beta_{t+1 \mid t}\right), \\
P_{t \mid T}\left(S_{t+j}\right)= & P_{t \mid t}+\tilde{P}_{t}\left(S_{t+j}\right) \\
& \times\left(P_{t+1 \mid T}-P_{t+1 \mid t}\left(S_{t+j}\right)\right) \tilde{P}_{t}\left(S_{t+j}\right),
\end{aligned}
$$

where $\tilde{P}_{t}\left(S_{t+j}\right) \equiv P_{t \mid t} P_{t+1 \mid t}\left(S_{t+j}\right)^{-1}$ and collapsing across states occurs each period as in Equations A.13 and A.14.

\footnotetext{
${ }^{20}$ For the random walk case, we set an arbitrary initial estimate of the term premium, but assign this guess an extremely large variance.
} 